\title{
Heat Transfer And Fluid Flow Analysis of a Novel Micro-Miniature Cryocooler Model
}

\author{
Husayn Bakhshy ${ }^{a}$, Seyyed Mohammad Ali Rohani ${ }^{\text {a }}$, Payam Heydari ${ }^{\text {b }}$, Reza Asadi a,* \\ a Department of Electrical and Computer Engineering, MalekAshtar University of Technology, Lavizan Street, \\ 15875-1774, Tehran, Iran. \\ $\mathrm{b}$ Department of Engineering, Roudehen Branch, Islamic Azad University, Roudehen, Iran. \\ *E-mail address: rasadi56@gmail.com, Corresponding author: Tel.: +98 (021)22959061
}

Received: 29 September 2018, Revised: 25 October 2018, Accepted: 14 November 2018

\begin{abstract}
A B S T R A C T
In the current study, a new model for micro-scale cooling systems is presented. The small-scale refrigerator is modeled by engraving channels and a micro nozzle on the sides of a rectangular glass. The system has the capability to reduce the temperature from $300 \mathrm{~K}$ to 80 in 5 seconds using nitrogen as the working fluid. The model consists of three elements, heat exchanger, nozzle and expansion tank and all the parts of the cooling system which is stationary. For this novel model, pressure drop through the channels and nozzle sections are presented and by using these information, temperature drop through the nozzle is obtained regarding the high Mach number at the throat of the convergencedivergence micro-nozzle. Due to the characteristics of this in-plane micro-nozzle, the heat exchange is modeled through the time in the glass, and temperature of the cooling system is also reported.
\end{abstract}

Keywords: Micro-miniature cooler, Joule Thomson cooler, heat transfer characterization, performance analysis, micro cooler.

\section{G R A P H I C A L A B S T RA C T}

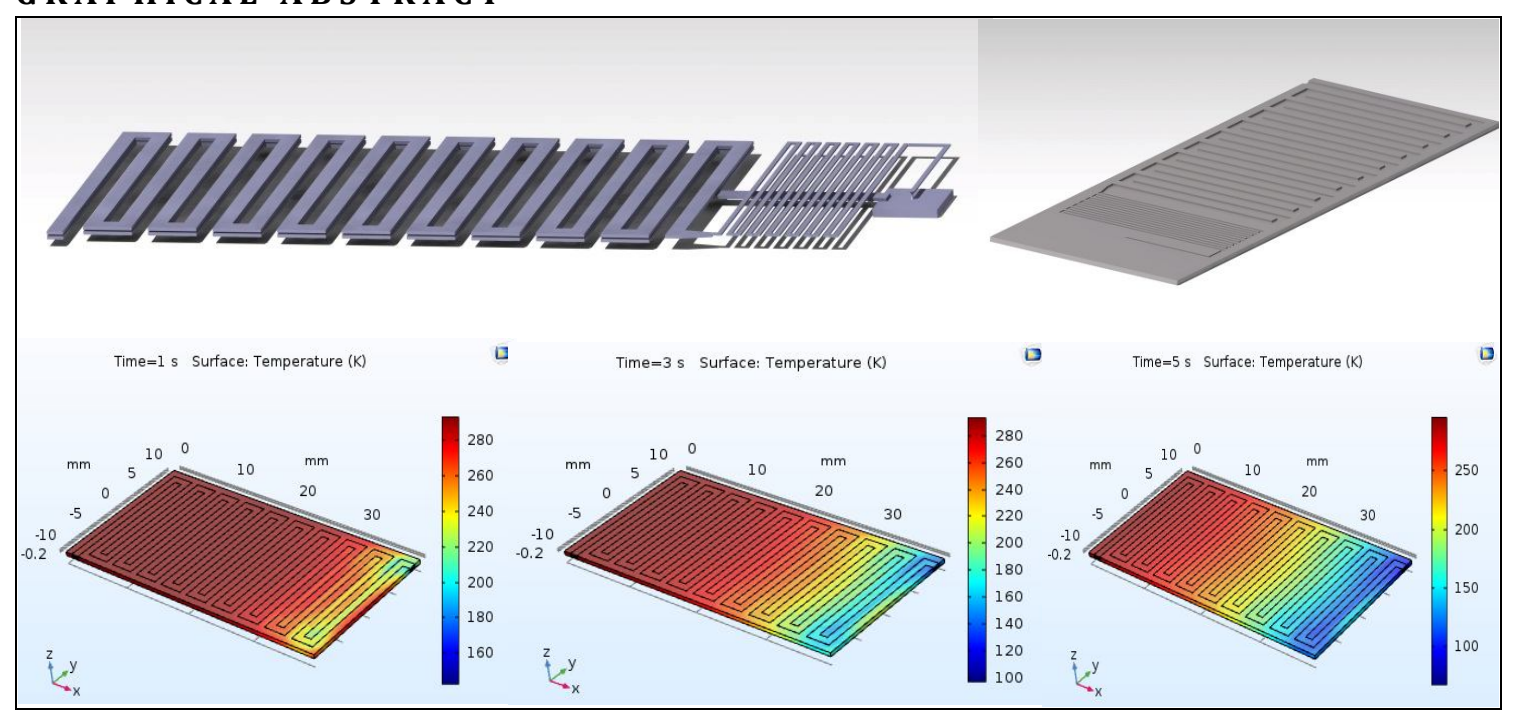




\section{Introduction}

Small-scale refrigerators are being widely used in cooling electronic components such as power intensive electronic component [1-4]. These systems have the ability to significantly decrease the temperature through a small period of time. In general, refrigerators using Joule-Thomson expansion can be classified depending on the shapes and designs. Miniature Joule-Thomson coolers with helical tube heat exchangers are one of the well-known models. $\mathrm{Ng}$ et al. [5] experimentally and numerically modeled a micro Joule-Thomson cooler using the helical tube exchanger model. The temperature was decreased to $96 \mathrm{~K}$ in the steady state model using argon as the working fluid and varying pressures from 200 bar to 1 bar. Xue et al. [6] experimentally and theoretically analyzed the performance of the helical tube Hampson-type heat exchanger of a miniature Joule-Thomson cooler for steady state stage of the system. It was concluded that the effectiveness decreases as inlet pressure rises, but the overall effectiveness exceeds 95\%. Moreover, it was found that the ratio of total loss of longitudinal heat conduction to flow loss indicates that the flow loss still occupies a great portion in the Hampson-type heat exchanger in spite of miniaturization in size. Since the helical tube exchanger model fail to cool down the fluid in a short period of time, inplane micro-scale heat exchangers got introduced. Micro-scale plane refrigerators have the advantage of less moving of mechanical parts which makes them more applicable and less sensitive to corrosion, break and damages. In the past decades, there have been some experimental studies on micro-scale coolers and cryogenic systems. Lerou et al. [7] investigated a new model for micro-scale plane refrigerators. This model included three layers to separate the inlet and outlet gas with external dimensions as $20 \times 1.7 \times 0.31 \mathrm{~mm}$. This model had the capability to cool nitrogen down to $96 \mathrm{~K}$ with $10 \mathrm{~mW}$ power. Lerou et al. [8] also modeled a two stage micro cooler system using three layers of glass and decreasing the temperature under $120 \mathrm{~K}$ by reducing the pressure from 80 bar to 6 bar. In this model they used two different gases, nitrogen and neon, in which the first stage of the cooling system acted as a precooling part of the second system. They concluded that the two stage model was not efficient since the heat leakage and the contact surfaces were not efficient. Derking et al. [9] present a single stage micro-scale cooler using adhesive bonding technique. In this model, the fluid was cooled down to $100 \mathrm{~K}$ and $140 \mathrm{~K}$ when using nitrogen and methane, respectively. Cao et al. $[10,11]$ designed a new model for inplane micro coolers with two stages of heat transfer. Three layers were used to produce this model and it had the capability to decrease the temperature up to $80 \mathrm{~K}$ using nitrogen as the working fluid. The inlet and outlet pressures of the gas were 100 atm and 1 atm, respectively. Little [12, 13] used photolithography to model a micro-scale JouleThomson cooler. Nitrogen was used as the working fluid and the temperature was decreased to $80 \mathrm{~K}$ by reducing pressure from 100 atm to 1 atm reaching to high Mach numbers in the nozzle. 


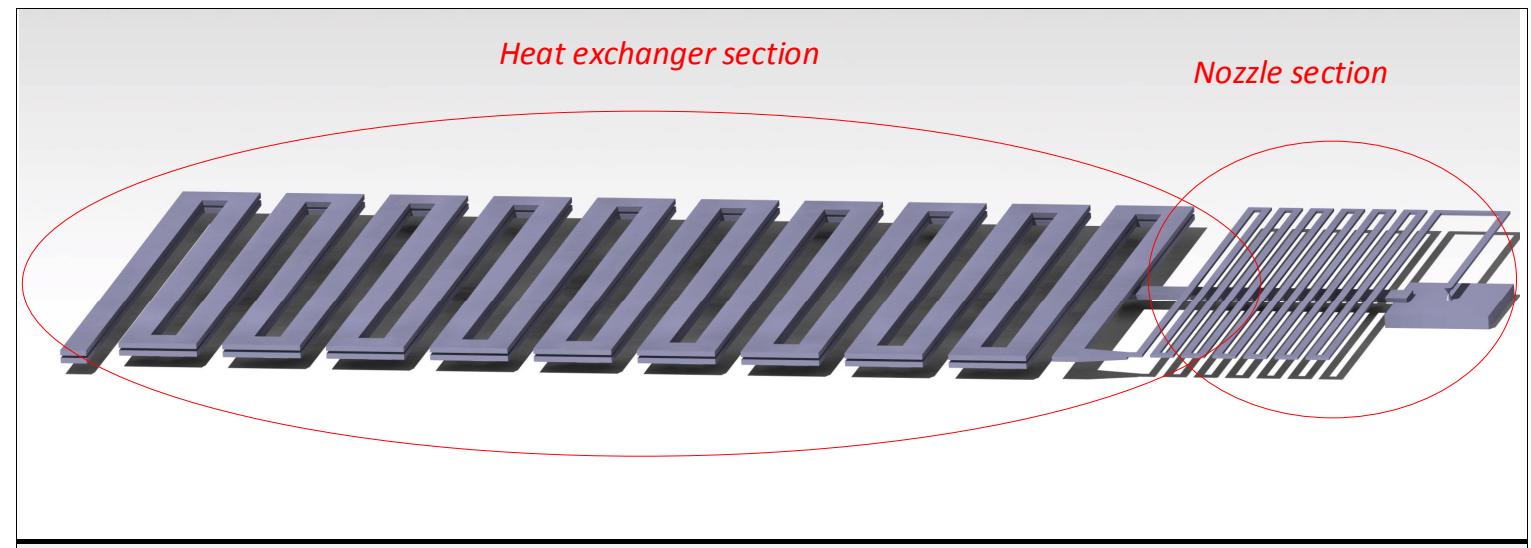

Figure 1. Schematic representation of fluid path through the micro-cooler.

\section{Microminiature Refrigerator Model}

In this study, the micro-scale cooler is carved inside a double-layered square plate which is shown in Figure 1. As shown, the model contains two main parts, heat exchanger and the nozzle which also contain an expansion tank where the cold fluid will be stored. Figure 2. demonstrates the geometrical dimensios of this channels in the glass plate. As shown, width of the heat exchanging channels are assumed to be $1 \mathrm{~mm}$ with a $1 \mathrm{~mm}$ wall between them. Moreover, the material is assumed to be Pyrex 7740. In this new model, hot fluid part is engraved on the top side and the cold fluid is in the bottom making the heat exchange possible. The nozzle section includes two main subsections, first the convergence nozzle which decreases the width of channels from $1 \mathrm{~mm}$ to $300 \mu \mathrm{m}$ allows the fluid to increase the velocity and decrease the pressure. Secondly, it is through the glass that the chocking and expansion mainly occur. It is important to reach to Mach 1 in the throat of the second nozzle to have high Mach numbers at the divergence side of the nozzle. This makes the adiabatic expansion more efficient and the temperature drop will be higher.

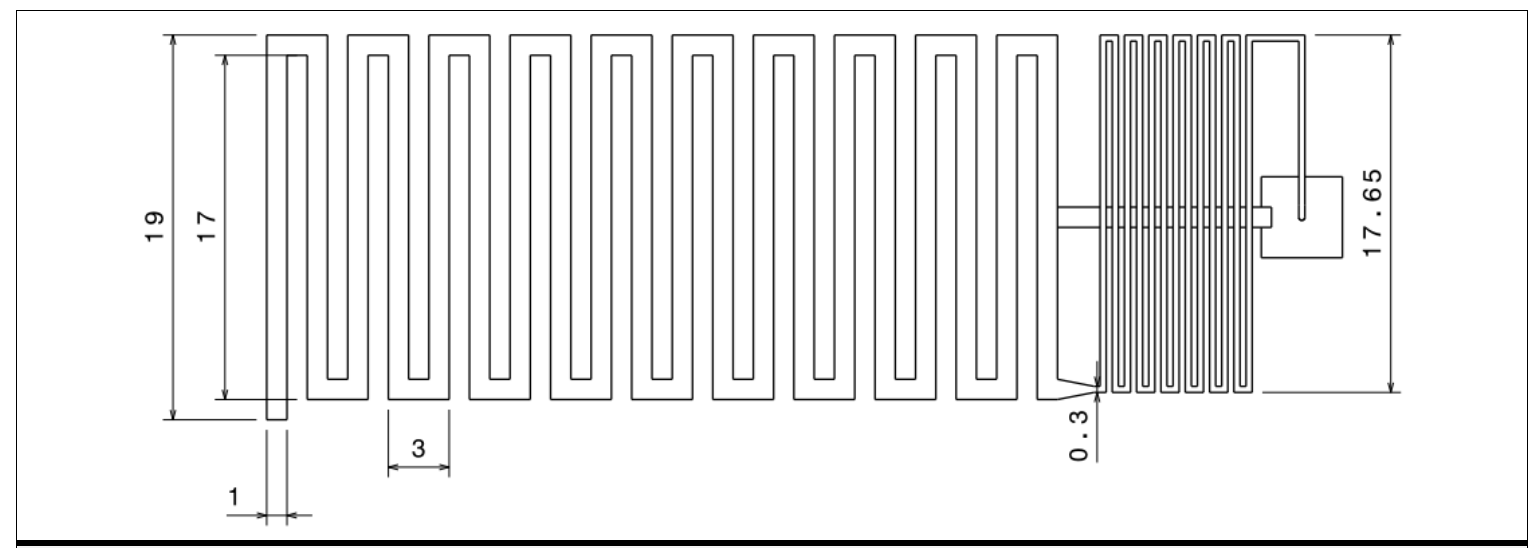

Figure 2. Dimensions of the engraved path inside the glass. 
Moreover, the nozzle is designed as shown in Figure 3 with the given dimensions. Afterward, there is a convergence-divergence nozzle as two connected cones with the highest radius $300 \mu \mathrm{m}$ and lowest at the throat $50 \mu \mathrm{m}$ making it possible to reach to Mach 1 at the throat. Then, the fluid is expanded in the divergence nozzle and then, throttling occurs. This adiabatic expansion will cause a considerable temperature drop in the expansion tank which is attached to the divergence nozzle.
In the first step, the pressure-drop inside the system is studied. The inlet pressure is assumed to be $300 \mathrm{~atm}$ and the outlet pressure is $1 \mathrm{~atm}$ and accordingly, in Figure 4, the pressure drop is illustrated. There are also two probes defined on the inlet and outlet sections of the nozzle part of the system to demonstrate the average pressure of these sections. From the results, the pressure at the entrance and the end of the nozzle will be $283.65 \mathrm{~atm}$ and $28.6 \mathrm{~atm}$, respectively.

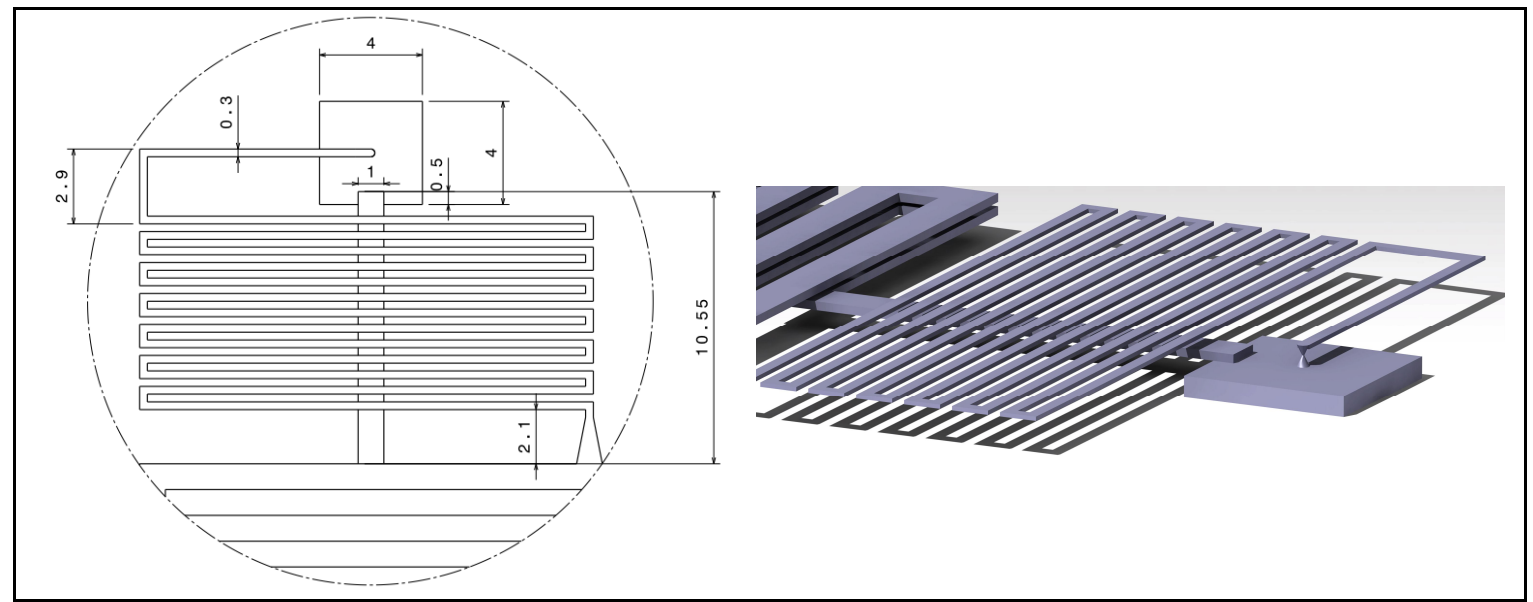

Figure 3. Dimensions of the engraved path inside the glass.

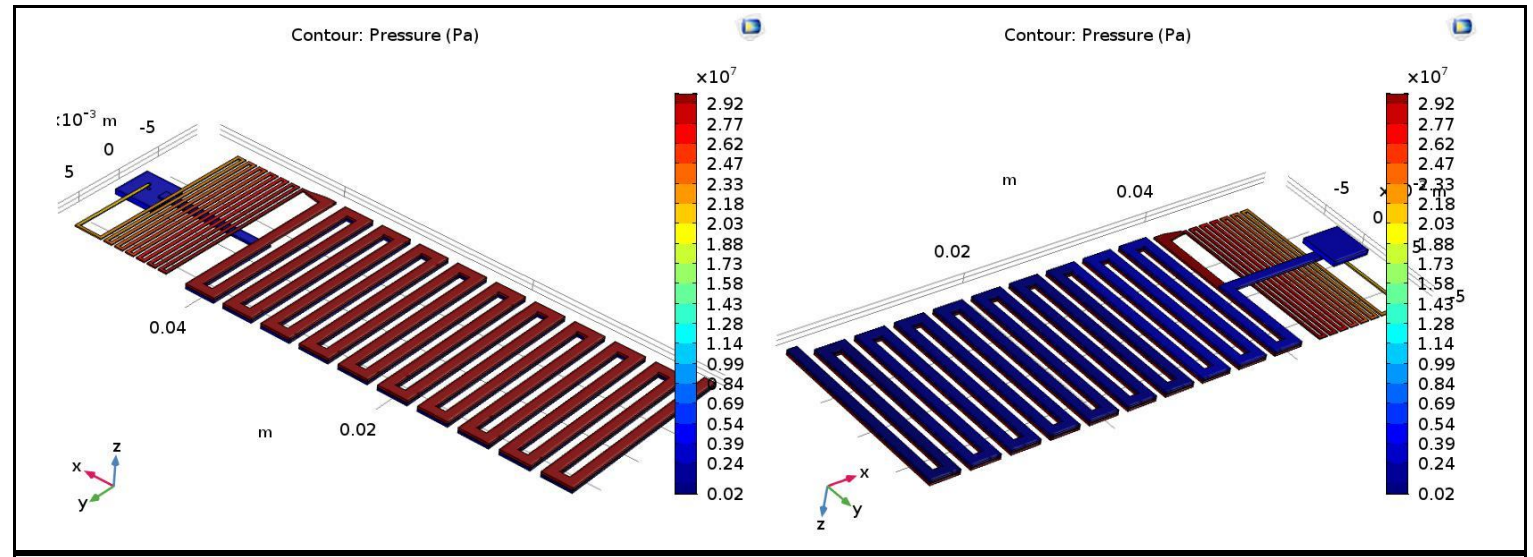

Figure 4. Pressure drop through the system. 
Table 1. Temperature drop in the nozzle section with respect to the inlet temperature

\begin{tabular}{cccc}
\hline $\boldsymbol{T}_{\text {in }}$ & $\boldsymbol{T}_{\text {out }}$ & $\boldsymbol{T}_{\text {in }}$ & $\boldsymbol{T}_{\text {out }}$ \\
\hline 300 & 222 & 200 & 186.9 \\
280 & 210.2 & 180 & 134.4 \\
260 & 194.6 & 160 & 123.2 \\
240 & 202.1 & 150 & 111.9 \\
220 & 194.6 & 130 & 97 \\
200 & 186.9 & 125 & 93.3 \\
\hline
\end{tabular}

By having the input and output pressrues of the nozzle, temperature drop for this part of the system, due to the irreversible adiabatic expansion through the convergence-divergence nozzle, is investigated. Table 1 demonstrates the temperature decrement in the nozzle section due to the pressure drop. Results of this table is used for curve using MATLAB to indicate the relation between the inlet and outlet temperature of the nozzle section which follows a linear function as:

$T_{\text {out }, \text { nozzle }}=0.5358 T_{\text {in, nozzle }}+0.8875$

where $T_{\text {in, norgle }}$ and $T_{\text {out morgle }}$ demonstrate the average inlet and outlet cross sections temperatures. By having the characteristics of the nozzle section, the heat exchanger part can be analyzed.

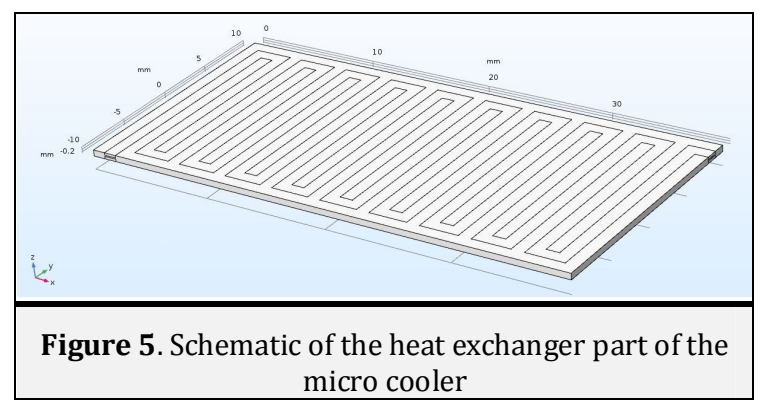

Figure 5 indicates the schematic of the heat exchanger part of the micro cooler. There are four important temperatures in this analysis. $T_{i n}$ is the inlet temperature of the nitrogen which, in this study, is assumed to be constant as $300 \mathrm{~K}$. Tout $_{\text {ou }}$ is the outlet temperature of the system which is unknown and it will vary through the time.

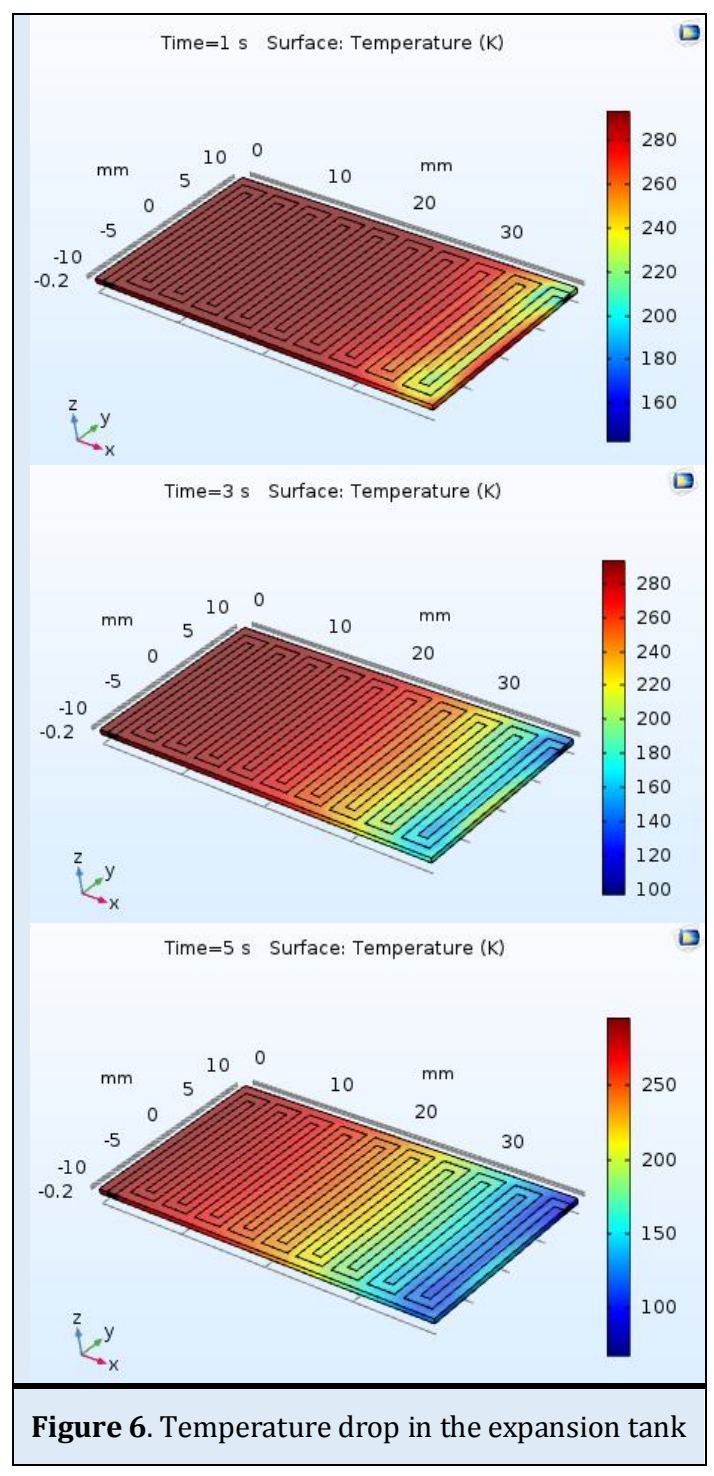

$T_{1}$ is the temperature of the outlet fluid in the high pressure channel which is equal to the input temperature of the nozzle section $\left(T_{i n_{t} \text { noggle }}\right) \cdot T_{2}$ is the temperature of the inlet fluid in the low 
pressure channel which is equal to the outlet temperature of the nozzle ( $\left.T_{\text {out noggle }}\right)$. Although both temperature $T_{1}$ and $T_{2}$ are unknown but they follow constrain defined in Eq. (1). Accordingly, by having the pressures on each boundary, heat exchange through the time between the high pressure and low pressure channel is obtained.

Figure 6 demonstrates the temperature variation in the micro cooler for $\mathrm{t}=[5,10$ and 15] seconds. From the results, it is seen that the temperature variation is considerable at the beginning of the operation and by decreasing the temperature its influence decreases. Figure 7 shows the average temperature of the gas in the entrance and exit sections of the nozzle. It is shown that after 5 seconds, temperature reaches to around $80 \mathrm{~K}$ with is about $220 \mathrm{~K}$ temperature decrement.

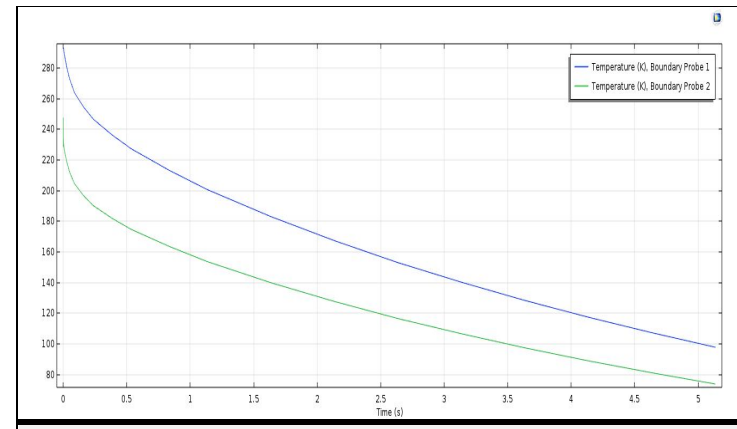

Figure 7. Temperature drop in the expansion tank

\section{Conclusion}

A general effective model for micro-scale cooling systems is presented containing three main sections with two layers. All parts of the cooler are stationary, protecting the system from dynamic failure. The heat exchanger section is as channels on two layers making heat exchange through the glass possible. The nozzle which is modelled and two cones are penetrated through the layers from the hot fluid side to the cold side. The pressure-drop through the system is modelled and it was concluded that through the nozzle the most pressure-drop is obtained. Since this pressure-drop is done in an adiabatic process, temperature has drop remarkably. It is concluded that for the model presented in this study, by having nitrogen as the operating fluid with $300 \mathrm{~atm}$ and $1 \mathrm{~atm}$ as the highest and lowest pressures of the system, the cooler is capable of cooling the fluid from $300 \mathrm{~K}$ to $80 \mathrm{~K}$ in about 5 seconds. Since the nozzle is designed as a convergence -divergence micro-nozzle high Mach numbers are achieved in the throat and accordingly the temperature significantly drops making the system more efficient.

\section{References}

[1]. C.J. Lasance, R. E. Simons, Electron. Cool., 2005, 11, 22-39.

[2]. K. Vafai, L. Zhu, Int. J. Heat. Mass. Tran., 1999, 42, 2287-2297.

[3]. L. Micheli, N. Sarmah, X. Luo, K.S. Reddy, T.K. Mallick, Renew. Sustain. Energ. Rev., 2013, 20, 595-610.

[4]. B. Gromoll, Thermal Management of Electronic Systems, Springer: Dordrecht, 1994, p 223.

[5]. K.C. Ng, H. Xue, J.B. Wang, Int. J. Heat. Mass. Tran., 2002, 45, 609-618.

[6]. H. Xue, K.C. Ng, J.B. Wang, Appl. Therm. Eng., 2001, 21, 1829-1844. 
[7]. P. Lerou, H. Jansen, G.C.F. Venhorst, J.F. Burger, T.T. Veenstra, H. Holland, H. Rogalla, Cryocoolers., 2005, 13, 489-496.

[8]. P. Lerou, H.J. Brake, H.V. Jansen, J.F. Burger, H.J. Holland, H. Rogalla, AIP Conf. Proc., 2008, 985, 614-621.

[9]. J.H. Derking, H.J. Holland, T. Tirolien, H.J. Brake, Rev. Sci. Instrum., 2012, 83, 045117.

[10]. H.S. Cao, A.V. Mudaliar, J.H. Derking, J.H., Lerou, P. Holland, D.R. Zalewski, H.J. M. Brake, Cryogenics., 2012, 52, 51-57.
[11]. H.S. Cao, S.Vanapalli, H.J. Holland, C.H. Vermeer, H.J. Brake, Int. J. Refrig., 2016, 69, 223-231.

[12]. W.A. Little, Physica B+C., 1982, 109, 20012009.

[13]. W.A. Little, Rev. Sci. Instrum., 1984, 55, 661680.

How to cite this manuscript: Husayn Bakhshy, Seyyed Mohammad Ali Rohani, Payam Heydari, Reza Asadi, Heat transfer and fluid flow analysis of a novel micro-miniature cryocooler model, Adv. J. Chem. A, 2018, 1, 32-38. 